\title{
Management of Traumatic Herniation of Buccal Fat Pad in a 22-month-old Child: A Case Report
}

\author{
Bhawana Sigdel, ${ }^{1}$ Sneha Shrestha, ${ }^{2}$ Mamta Dali, ${ }^{3}$ Amita Rai, ${ }^{4}$ Ashish Shrestha, ${ }^{5}$ Bandana Koirala ${ }^{6}$ \\ ${ }^{1}$ Post-graduate Resident, ${ }^{2}$ Assistant Professor, ${ }^{3}$ Associate Professor, ${ }^{4}$ Consultant, ${ }^{5,6}$ Professor \\ ${ }^{1-3,6}$ Department of Pedodontics and Preventive Dentistry, B.P. Koirala Institute of Health Sciences, Dharan, Nepal, \\ ${ }^{4}$ Kanti Children's Hospital, Kathmandu, Nepal, ${ }^{5}$ Department of Oral Pathology B.P. Koirala Institute of Health Sciences, Dharan, Nepal
}

\begin{abstract}
The buccal fat pad is an encapsulated mass located within the buccal facial spaces. It is relatively large in neonate and infants. A tiny perforation on buccal mucosa, fascia or buccinator muscle can lead to the herniation of buccal fat pad in young children. Trauma is the most common etiology. Such situation demands careful examination of oral cavity and thorough history taking to avoid any misdiagnosis. This paper reports a clinical presentation and management of herniation of buccal fat pad on a 22-month-old-girl following trauma to her left cheek region with sugarcane.
\end{abstract}

Keywords: Buccal fat pad, excision, herniation.

\section{INTRODUCTION}

Buccal fat pad is a specialized type of adipose tissue that serves to line the masticatory space, separating muscles of mastication from each other and from the zygomatic arch and the ramus of mandible. It has got four processes: buccal, pterygoid, superficial, and deep temporal processes. The pterygoid and temporal processes are situated deep whereas the buccal extension is located superficially within the cheek. ${ }^{1}$ Buccal fat pad is prominent in young children and is responsible for the fullness of the cheeks. It aids in cushioning and sucking functions and is often referred to as sucking or suctorial pad. ${ }^{2}$ Bichat (1802) first described the true fatty nature of buccal fat pad. ${ }^{3}$ Earlier, it was accidentally encountered during various operations in the maxillofacial region and had little importance. ${ }^{2}$ However, these days it is considered as an ideal flap to reconstruct oral defect due to its high vascularity, ease of mobilization and minimal donor site morbidity. ${ }^{4}$

\section{Correspondence}

Dr. Bhawana Sigdel

Post Graduate Student, Department of Pedodontics and

Preventive Dentistry, BPKIHS, Dharan, Nepal.

E-mail: bhawana.sigdel@gmail.com

\section{Citation}

Sigdel B, Shrestha S, Dali M, Rai A, Shrestha A, Koirala B. Management of Traumatic Herniation of Buccal Fat Pad in a 22-month-old Child: A Case Report. J Nepalese Assoc Pediatr Dent. 2020;1(1):17-9.
Traumatic herniation is a rare entity commonly seen in infants and young children from five months to12 years. ${ }^{5}$ Perforation of buccinator muscle due to blunt injury of buccal mucosa by any foreign objects is the cause of large portion of buccal fat pad to herniate into the oral cavity. At the same time, sucking activity of infants further promotes its herniation through the mucosal defect. ${ }^{6}$

\section{CASE REPORT}

A 22-month-old female child reported to the Department of Pedodontics and Preventive Dentistry, BPKIHS, Dharan with the chief complaint of swelling on left cheek region. There was a history of traumatic injury while eating sugarcane twenty-four hours back. Parents noted an extruding mass with minimal bleeding from the site of injury though it did not cause any difficulty in eating or breathing. The medical history was not significant.

On examination, extraoral swelling was present on the left cheek region. Intraorally, reddish yellow, soft pedunculated mass measuring $2 \times 1 \times 1 \mathrm{~cm}$ size was seen protruding inferior and distal to the left parotid papilla (Figure 1), with no active bleeding. Henceforth, the clinical diagnosis of herniation of buccal fat pad was made.

The necrotic mass was surgically excised under local anesthesia and healthy tissue was repositioned back followed by primary closure using 4-0 vicryl resorbable suture (Figure 2). The excised mass was sent for 


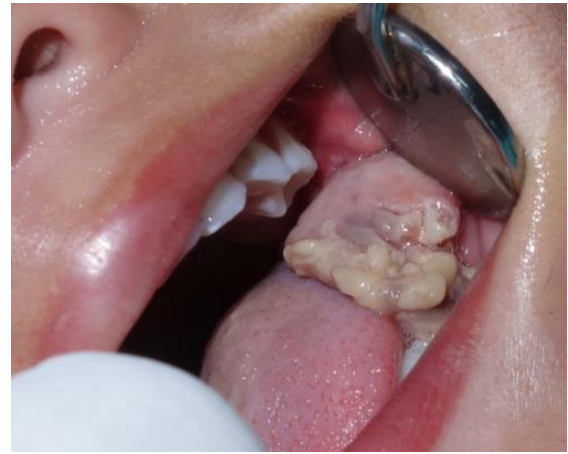

Figure 1. Intraoral herniated buccal fat pad.

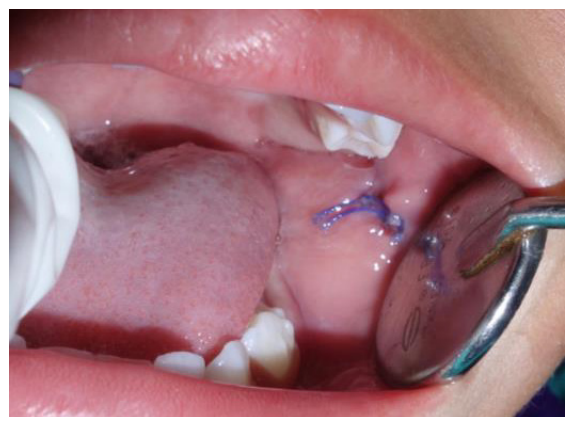

Figure 4. Satisfactory healing after one week.

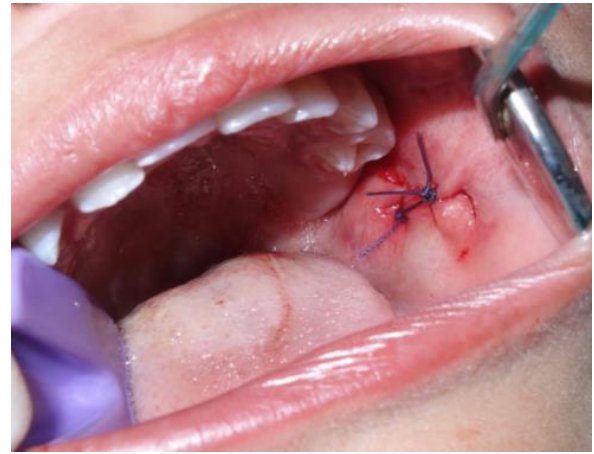

Figure 2. Excision and primary closure (vicryl suture).

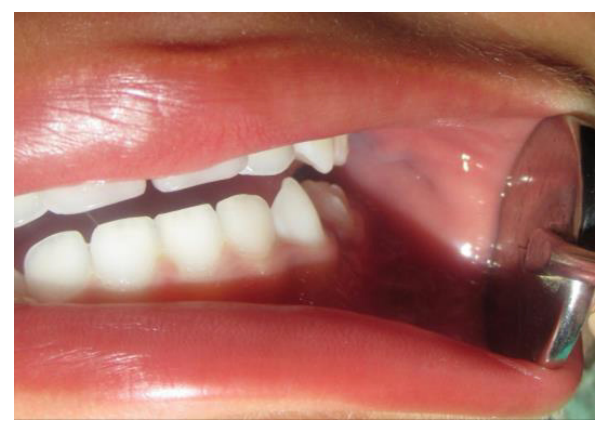

Figure 5. Four months follow up showing complete healing.

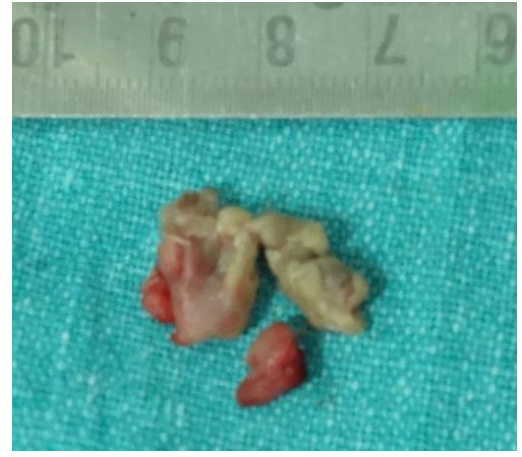

Figure 3. Excised mass from buccal fat pad.

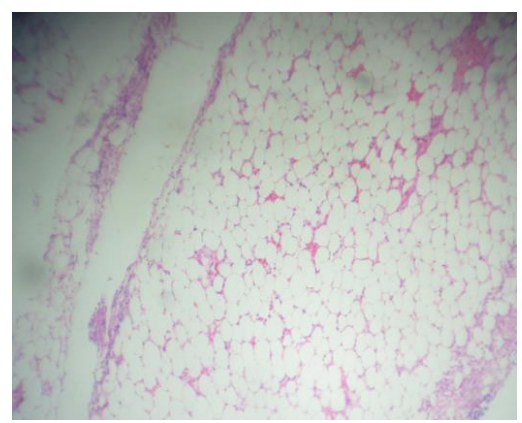

Figure 6. Photomicrograph showing numerous fat cells in the loose fibrousstroma and inflammatory cells $(\mathrm{H} \& \mathrm{E} ; 4 \mathrm{X})$. histopathological examination (Figure 3). Antibiotics, antiinflammatory drugs and antiseptic mouthwashes were prescribed and satisfactory healing was observed one week postoperatively (Figure 4). The patient came for follow up after four months and it showed normal healed area (Figure 5).

Histopathologically it showed aggregates of numerous normal adipocytes with peripherally placed nuclei and central vacuolization in a fibrous connective tissue along with numerous endothelial cells lined blood vessels and dispersed inflammatory cells, predominantly lymphocytes (Figure 6).

\section{DISCUSSION}

Intraoral buccal fat pad herniation is seen frequently in young children. This is due to children's propensity to place every reachable object (sharp, pointed sticks, toys, lead pencil, comb, toothbrushes etc.) in their mouth making them extremely vulnerable to oral injuries. An interesting characteristic of this lesion is that the size of the extruded mass is greater than the site of injury. ${ }^{5}$ According to a report by Abdulai et al., ${ }^{7}$ male children are more prone to injury due to their active and adventurous nature as compared to girls. But in our case, it was a girl child with her left buccal mucosa involved.

Depending upon the situation, herniation of buccal fat pad is managed by different approaches. If the herniated buccal fat pad mass is too large and necrosed, excision is treatment of choice. Alternative to excision, in cases where there is early evaluation and the protruded mass is small with minimal inflammatory changes, repositioning of the herniated mass to its anatomic position followed by primary closure can be done. Some cases reported that the approximate period between the injury and the first visit was less than four hours. ${ }^{8,9}$

Another better option for management could be the partial conservative excision, as an en-masse removal of the buccal fat pad may reduce cheek fullness and change facial contour. ${ }^{6}$ Wolford et al. ${ }^{10}$ surgically excised the lesion under general anesthesia in an 8-month-old girl. However in our case, we opted for the partial conservative excision which was carried out under local anesthesia.

Close proximity of buccal fat pad to the parotid gland 
and facial nerve demands for precise and careful wound management during treatment. Likewise, exploration for foreign body and proper irrigation is of utmost importance before closing the wound. The situation can be complicated by factors like occlusal trauma, inflammation, infection, salivary contamination, and necrosis of the tissue. ${ }^{6}$ Most of the cases reported had occurred at occlusal level near parotid papilla where prevention of damage to the parotid duct is very important. ${ }^{9}$ Timely management of the lacerated wound with proper oral hygiene maintenance gives satisfactory healing in terms of both physical and psychological aspects.

The differential diagnosis of buccal fat pad herniation includes tumors like lipoma; salivary gland neoplasm, hemangioma, and traumatic fibroma. ${ }^{3}$ Features that confirm the diagnosis are history of trauma, site of injury, fatty appearance of lesion and histopathology.

\section{CONGLUSIONS}

Traumatic herniation of buccal fat pad though rare, presents with a challenging scenario to manage. In the present case, the herniated buccal fat pad did not directly involve any of the vital structures. The excision and repositioning back of the healthy tissues with primary closure should be taken with care to avoid injury to vital structures and asymmetry or facial dysmorphosim.

Conflict of Interest: None

JNAPD

\section{REFERENCES}

1. Zhang HM, Yan YP, Qi KM, Wang JQ, Liu ZF. Anatomical structure of the buccal fat pad and its clinical adaptations. Plastic and Reconstructive Surgery. 2002 Jun;109(7): 2509-18. [Pub Med I DOI]

2. Singhal M, Sagar S. Post Traumatic Buccal Fat Pad Injury in a Child: A missed entity in ER. Oman Medical Journal. 2010 Jul;25(3):e002. [PubMed I DOI]

3. Zipfel TE, Street DF, Gibson WS, Wood WE. Traumatic herniation of the buccal fat pad: a report of two cases and a review of the literature. Int J Pediatr Otorhinolaryngol. 1996 Dec 20;38(2):175-9. [PubMed I DOI]

4. Baumann A, Ewers R. Application of the buccal fat pad in oral reconstruction. J Oral Maxillofac Surg. 2000 Apr;58(4):389-92; discussion 392-3. [PubMed I DOI]

5. Gadipelly S, Sudheer MV, Neshangi S, Harsha G, Reddy V. Traumatic herniation of buccal fat pad in 1 year old child: case report and review of literature. J Maxillofac Oral Surg. 2015 Mar;14(Suppl 1):435-7. [PubMed I DOI]

6. Patil R, Singh S, Subba Reddy VV. Herniation of the buccal fat pad into the oral cavity: a case report.J Indian Soc Pedod Prev Dent. 2003 Dec;21(4):152-4. [PubMed]

7. Abdulai AE, Avogo D. Traumatic herniation of the buccal fat pad: A case report. Ghana Medical Journal. 2004 Sep;38(3):120-2. [Full Text I DOI]

8. Fleming P. Traumatic herniation of buccal fat pad: a report of two cases. Br J Oral Maxillofac Surg. 1986 Aug;24(4):265-8. [PubMed I DOI]

9. Horie N, Shimoyama T, Kaneko T, Ide F. Traumatic herniation of the buccal fat pad. Pediatr Dent. 2001 May-Jun;23(3):249-52. [PubMed]

10. Wolford DG, Stapleford RG, Forte RA, Heath M. Traumatic herniation of the buccal fat pad: report of case.J Am Dent Assoc. 1981 Oct;103(4):593-4. [PubMed IDOI] 